\title{
Magnetic Resonance Evaluation of Coronary Anatomy, First-Pass Myocardial Perfusion and Late Gadolinium Enhancement in children and Young Adults with Acquired and Congenital Heart Disease
}

Dilachew Adebo ( $\square$ Dilachew.A.Adebo@uth.tmc.edu )

University of Texas Medical School at Houston https://orcid.org/0000-0002-5848-9238

John Brownlee

Driscoll Children's Hospital

Cesar Gonzalez de Alba

Driscoll Children's Hospital

Fernando Molina Berganza

Driscoll Children's Hospital

John Mark Morales

Driscoll Children's Hospital

\section{Research Article}

Keywords: Cardiac magnetic resonance imaging, Coronary anatomy, first pass myocardial perfusion and late gadolinium enhancement

Posted Date: March 3rd, 2021

DOI: https://doi.org/10.21203/rs.3.rs-262524/v1

License: (c) (1) This work is licensed under a Creative Commons Attribution 4.0 International License.

Read Full License 


\section{Abstract}

Introduction

Cardiac magnetic resonance (CMR) has expanded its role in the diagnosis and management of congenital heart disease and acquired heart disease in children. However, there are few studies evaluating the role of cardiac magnetic resonance delineating the anatomy of coronary arteries along with assessment of first pass myocardial perfusion in children. The purpose of this study is to evaluate the extensive use of CMR for delineating coronary anatomy, evaluating first pass myocardial perfusion and late gadolinium enhancement in children with acquired and congenital heart disease.

Methods

A retrospective review of 81 consecutive CMR Whole Heart T2 Prep coronary angiography studies of patients with congenital and acquired heart disease that were performed from December 2013 to May 2015. Results of first pass myocardial perfusion study (at rest and with adenosine stress) and Late Gadolinium enhancement imaging findings were also reviewed.

Results

The median age at the time of CMR was 14 years with range of 2 months to 35 years of age with 46 male and 35 female subjects. Tetralogy of Fallot was the most common pre CMR diagnosis with almost $30 \%$ $(24 / 81)$ of all subjects, followed by suspected coronary artery anomaly in $18.5 \%$ (15/81) of all subjects. First pass myocardial perfusion defects were identified in $2.5 \%(2 / 81)$ of subjects. Delayed myocardial enhancement study was performed in $83 \%$ (67/81) of all patients, with an abnormal result identified in $28.3 \%$ (19/67) of these subjects. The left coronary origin, proximal course and proximal branches were visualized in $94 \%(76 / 81)$ of the subjects. The right coronary origin and proximal course was visualized in about $89 \%(72 / 81)$ of subjects. We found good diagnostic quality images in $90 \%$ $(73 / 81)$ of the subjects. Abnormal coronary artery origin was observed in about $9 \%$ of all subjects $(7 / 81)$. Coronary aneurysmal malformations were identified in $6 \%$ of all subjects $(5 / 81)$. We were unable to visualize either one of the coronary arteries in about $9 \%$ of subjects $(7 / 81)$ either due to patient movement during the study, metallic artifacts or extremely fast heart rate.

Conclusions

Cardiac magnetic resonance imaging can reliably evaluate the coronary anatomy, first pass myocardial perfusion defect and myocardial scar in a diverse group of patients with acquired and congenital heart diseases.

\section{Introduction}

The assessment and evaluation of patients with congenital and acquired heart disease requires a thorough clinical investigation with the support of different imaging modalities [1]. Echocardiography has 
invariably become the first line imaging study for the vast majority of these patients, both pre and post operatively, as it provides diagnostic anatomical and functional images, while being portable and noninvasive at the same time. However, some of its limitations include less accurate information in those patients with poor acoustic window as well as limited thoracic vasculature and coronary artery evaluation, among others $[2,3]$.

Cardiac magnetic resonance (CMR) has expanded its role in the diagnosis and management of congenital and acquired heart disease in children and young adults for the past 20 years [4-7]. It provides high quality images that help outline complex thoracic vasculature, cardiac anatomy,

coronary arteries (including vessel wall), cardiac function and viability assessment, as well as cardiac perfusion, with the benefit of obviating the risks from invasive catheterization, iodinated contrast agent use and ionizing radiation exposure [8-10].

Anomalous coronary arteries may be assessed through magnetic resonance angiography (MRA), often with superior reconstruction and results compared to x-ray angiography [11,12]. It is the preferred test for younger patients with both suspected and/or known anomalous coronary artery origin as well as for those with other concomitant cardiac pathologies (13).

Clinically accepted indications of coronary MRA are limited to the assessment of coronary artery anomalies (class I indication) such as aneurysms (i.e. Kawasaki disease) and aorto-coronary bypass grafts (class II indication). Respiratory motion artifacts, usually regarded as a known CMR limitation, can be decreased through prospective real-time navigator gating and correction techniques [14-16].

Coronary aneurysmal disease or ectasia in children is mainly caused by Kawasaki disease, followed by congenital causes. Inflammatory and other connective tissue disorders such as Takayasu's arteritis, lupus, rheumatoid arthritis, Marfan syndrome, among others, have also been described to cause them [17, 18]. Mavrogeni et al demonstrated that MRI can effectively identify coronary disease in patients with Kawasaki disease and other autoimmune diseases, and that in fact MRA is equal to quantitative coronary angiography, with the additional advantage of being a noninvasive study [19-21].

Preliminary data in the past suggested that MRI coronary angiography could be used as a screening test to exclude clinically important stenosis in patients who would have been referred for diagnostic contrast angiography [22]. Nowadays, comparisons between CMR and computerized tomography (CT) angiography have demonstrated to similarly identify significant coronary stenosis in patients with suspected or known coronary artery disease [23].

Cardiac magnetic resonance imaging has been demonstrated to detect magnitude of infarcted myocardium along with delineation of origin and proximal course of coronary arteries [24-27]. In their multicenter trial, Kato et al found that whole-heart coronary MRA can noninvasively detect significant coronary artery stenosis with a sensitivity of $88 \%$ and specificity of $72 \%$ [28]. 
Contrast enhancement in coronary MRA may help to decrease the T1 relaxation time for blood, which in turn allows for an increased contrast-to-noise ratio for coronary MRA [29].

CMR has also significantly evolved in regards to perfusion imaging techniques to detect blood flow inside the myocardium. While single photon emission computed tomography (SPECT) has been regarded to be the clinical standard of myocardial perfusion, it does not come without some disadvantages such as ionizing radiation usage, poor spatial resolution, and artifacts secondary to soft tissue attenuation, among others. Myocardial perfusion imaging by first-pass contrast enhanced CMR measures the amount of contrast agent flowing within the myocardium during the first pass after a bolus injection of contrast is given. Myocardial areas with lesser local blood flow will look hypointense and may be detected provided there is acceptable image quality. First-pass contrast enhanced CMR myocardial perfusion can also provide quantitative measurements of blood flow, give estimates of myocardial flow reserve, and evaluate regions with prior myocardial ischemia [30-32].

Though there are multiple studies that evaluate the role of CMR in describing and assessing cardiac anatomy, ventricular function and major vessel anatomy [11,12,16,33-35], there are very few that describe the anatomy of coronary arteries in different congenital and acquired cardiac pathologies along with assessment of first pass myocardial perfusion in children and young adults. In this study we discuss the extensive use of CMR for delineating coronary artery anatomy, evaluating first pass myocardial perfusion and late gadolinium enhancement in children and young adults with acquired and congenital heart disease.

\section{Methods}

Patients: This is a retrospective review of 81 consecutive CMR Whole Heart T2 Prep coronary angiography studies of patients with congenital and acquired heart disease that were performed from December 2013 to May 2015. Results of first pass myocardial perfusion study (at rest and with adenosine stress) and late Gadolinium enhancement imaging findings were also reviewed. This study was approved by institutional review board of the hospital.

Magnetic Resonance acquisition: All CMR studies were performed on 1.5 Tesla Ingenia (Philips). Respiratory navigated ECG gated acquisition was performed to obtain T2 prep whole heart coronary images. Majority of the studies were performed without any sedation but few children younger than 9 years of age were sedated. Studies were post-processed on a satellite workstation and reviewed by experienced cardiologist in charge of the clinical MRI reporting.

Late gadolinium enhancement imaging: Inversion recovery Gadolinium enhanced MR imaging was performed after intravenous injection of gadopentetate dimeglumine by using T1 weighted imaging technique in the cardiac short axis, four chamber view, and left ventricular two chamber. The inversion time was obtained by look-locker technique for optimal suppression of normal myocardial signal. 


\section{Results}

The median age at the time of CMR was 14 years with range of 2 months to 35 years of age with 46 male and 35 female patients. Among the patient's pre-CMR diagnosis (Table 1), tetralogy of Fallot was the most common averaging $30 \%$ of all subjects $(24 / 81)$, followed by suspected coronary artery anomaly in about $19 \%$ of subjects $(15 / 81)$ of all subjects.

First pass perfusion defects were identified in $2.5 \%$ (2/81) of subjects. Delayed myocardial enhancement study was performed in $83 \%$ of all patients $(67 / 81)$, with an abnormal result identified in $28 \%$ of these subjects $(19 / 67)$.

In our patients' coronary artery study (Table 2), the left coronary origin, proximal course and proximal branches were visualized in about $94 \%(76 / 81)$ of the subjects. For the right coronary, its origin, proximal course and branches were visualized in $89 \%(72 / 81)$ of subjects. We found good diagnostic quality images in $90 \%(73 / 81)$ of all the subjects.

The different coronary artery findings can be observed in Table 3. The most common finding was clockwise rotation of coronary artery origin, seen in about $27 \%$ of subjects $(20 / 81)$. A proximal conal branch arising from proximal right coronary artery (RCA) and coursing anteriorly around the right ventricular outflow tract (RVOT) was observed in $16 \%$ of all subjects (13/81). The left anterior descending (LAD) artery was found to run close to the posterior aspect of the RVOT and in close proximity behind the right ventricle to pulmonary artery (RV-PA) homograft in about $9 \%$ of subjects each (14/81 total). The RCA was found to be smaller than the left coronary artery (LCA) in $6 \%$ of the subjects (5/81). An abnormal coronary artery origin was observed in almost $9 \%$ of all subjects $(7 / 81)$. Coronary aneurysmal malformations were identified in $6 \%$ of all subjects $(5 / 81)$. We were unable to visualize either one of the coronary arteries in about $9 \%$ of subjects $(7 / 81)$ either due to patient motion, artifacts or fast heart rate.

Ten patients (12\%) had a pre-CMR diagnosis of suspected abnormal coronary artery origin by echocardiogram (Table 4). From these, $70 \%$ (7/10) had a chief complaint of chest pain or syncope. Fifty percent of patients (5/10) had normal coronary arteries on CMR, while 40\% (4/10) had an abnormality in their origin or course. Only one patient's right coronary artery was not visualized due to an artifact caused by dental braces.

\section{Discussion}

Patients with complex congenital or acquired heart diseases require an in depth assessment of their cardiac anatomy and function through their life, by means of multiple and repetitive imaging studies [13]. CMR has expanded its role in the diagnosis and management of congenital and acquired heart disease in children and young adults by providing high quality images that not only help to outline complex thoracic vasculature, but also provides highly-detailed cardiac anatomy images, coronary artery course and vessel wall details, cardiac function and perfusion, with the benefit of obviating the risks from invasive catheterization, iodinated contrast agent use and ionizing radiation exposure [8-10]. 
In our study, we found that CMR provided good quality images in up to $90 \%$ of all patients with acquired and congenital heart diseases that highly delineated their coronary anatomy.

Nineteen subjects (28\%) had delayed myocardial enhancement abnormalities detected by CMR. In one of the subjects who had a history of Duchenne's muscular dystrophy, we found extensive myocardial delayed enhancement involving lateral, anterolateral and inferolateral walls of the left ventricle. We also identified a patch of delayed myocardial enhancement involving the interventricular septum but with normal coronary artery study (Figure 1). One patient with aortic stenosis had diffuse circumferential subendocardial delayed myocardial enhancement (Figure 2).

In our study population, $6 \%$ of patients $(5 / 81)$ had history of Kawasaki disease and CMR showed aneurysms involving multiple coronary arteries in four of the five subjects. One of these patients had a giant aneurysm of the right coronary artery with a partially occlusive thrombus in the aneurysmal right coronary segment. In this patient, there was a first-pass myocardial perfusion defect both at rest and with adenosine stress consistent with a fixed perfusion defect (irreversible ischemic change). This patient also had evidence of delayed myocardial enhancement involving the sub-endocardium which correlates with the area of the first-pass myocardial perfusion defect. (Figure 3).

Seven patients (8.64\%) had anomalous aortic origin of coronary arteries. One of them had anomalous origin of left coronary artery from right coronary sinus with inter-arterial course and underwent unroofing of the coronary artery. Post repair CMR showed a widely patent unroofed left coronary artery with normal first pass myocardial perfusion (at rest and with adenosine stress) and no evidence of delayed myocardial enhancement (Figure 4). Another patient had anomalous right coronary artery from the left coronary sinus with inter-arterial course and preoperative CMR demonstrating the anatomy of the anomalous coronary artery. The patient underwent successful unroofing of the anomalous right coronary artery. There was no evidence of delayed myocardial enhancement in this patient.

There were two patients (2.5\%) with Marfan's syndrome who underwent valve sparing aortic root replacement with coronary re-implantation. CMR showed widely patent re-implanted coronary arteries in one patient. In the second patient, the left coronary artery was demonstrated but the right coronary artery was not well visualized due to artifact from a spinal fusion rod. There was no evidence of myocardial scar or fibrosis in either of these subjects.

There were 22 patients $(27 \%)$ with a history of right-ventricle to pulmonary artery conduit placement. Coronary artery images by CMR were acquired in all patients, with good diagnostic quality images observed in $91 \%$ of them (20/22). Fifty nine percent of patients (13/22) had a history of tetralogy of Fallot. Nine patients (11\%) had a history of arterial switch operation for dextro-transposition of great arteries. Their coronary anatomy was well delineated with CMR (Figure 5). There was no evidence of myocardial scar or fibrosis on the late Gadolinium enhancement study of these subjects.

CMR was also performed in $12 \%$ of all patients $(10 / 81)$ who had a suspected abnormal coronary artery origin detected by echocardiogram. Normal coronary arteries were observed in $50 \%$ of these patients 
(5/10), while an abnormal origin or course was detected in $40 \%$ of them (4/10); two patients had a RCA arising from the left coronary sinus (Figure 6), while one patient had clockwise rotation of the origin of coronary arteries and another patient had fusion of right and left coronary cusps.

\section{Conclusions}

Cardiac magnetic resonance imaging is a valuable tool that can reliably evaluate the coronary anatomy, first pass myocardial perfusion defect and myocardial scar in children and young adults with acquired and congenital heart diseases.

\section{Abbreviations}

Atrioventricular (AV), delayed myocardial enhancement (DME), dextro, transposition of great arteries (dTGA), left anterior descending (LAD), left coronary artery (LCA), left ventricle (LV), magnetic resonance angiography (MRA), right coronary artery (RCA) , right ventricle to pulmonary artery (RV-PA), right ventricular outflow tract (RVOT).

\section{Declarations}

\section{Author contributions}

Study concepts, D.A., J.B., J.M.M., C.G.A., F.M.B.; study design, D.A., J.B., J.M.M., C.G.A., F.M.B.; literature research, C.G.A., F.M.B., D.A.; clinical studies, D.A., J.B., J.M.M.; data acquisition, D.A., C.G.A., F.M.B.; data analysis/interpretation, D.A., C.G.A., F.M.B., J.B., J.M.M. ; statistical analysis, D.A., C.G.A., F.M.B. ; manuscript preparation, D.A., C.G.A., F.M.B.; manuscript definition of intellectual content, D.A., J.B., J.M.M., C.G.A., F.M.B.; manuscript editing, D.A., C.G.A., F.M.B ; manuscript revision/review, D.A., J.B., J.M.M., C.G.A., F.M.B.; manuscript final version approval by all authors.

Funding: This research received no specific grant from any funding agency, commercial or non-for-profit sectors.

Conflict of interest: The authors declare that they have no conflict of interest.

Availability of data or material: Data is available up on request.

Code availability: Not applicable

Ethical Standard: This study was approved by Institutional Review Board of Driscoll Children's Hospital

Consent to participate: Not applicable.

Consent for publication: Not applicable 


\section{References}

1. Ntsinjana HN, Hughes ML, Taylor AM. The role of cardiovascular magnetic resonance in pediatric congenital heart disease. J Cardiovasc Magn Reson. 2011 Sep 21;13:51. doi: 10.1186/1532-429X13-51.

2. Lai WW, Geva T, Shirali GS, Frommelt PC, Humes RA, Brook MM,Pignatelli RH, Rychik J: Guidelines and Standards for Performance of a Pediatric Echocardiogram: A Report from the Task Force of the Pediatric Council of the American Society of Echocardiography. Journal of the American Society of Echocardiography 2006, 19:1413-1430.

3. Marx GR, Geve T (1998) MRI and echocardiography in children: how do they compare? Semin Roentgenol 3:281-292

4. Helbing WA, de Roos A. Clinical applications of cardiac magnetic resonance imaging after repair of tetralogy of Fallot. Pediatr Cardiol. 2000 Jan-Feb;21(1):70-9.

5. Srinivas B, Patnaik AN, Rao DS. Gadolinium-enhanced three-dimensional magnetic resonance angiographic assessment of the pulmonary artery anatomy in cyanotic congenital heart disease with pulmonary stenosis or atresia: comparison with cineangiography.Pediatr Cardiol. 2011 Aug;32(6):737-42.

6. Kellenberger CJ, Yoo SJ, Büchel ER. Cardiovascular MR imaging in neonates and infants with congenital heart disease. Radiographics. 2007 Jan-Feb;27(1):5-18.

7. Boechat MI, Ratib O, Williams PL, Gomes AS, Child JS, Allada V; Cardiac MR Imaging and MR Angiography for Assessment of Complex Tetralogy of Fallot and Pulmonary Atresia. RadioGraphics 2005, 25:1535-1546.

8. Faulkner K, Love HG, Sweeney JK, Bardsley RA. Radiation doses and somatic risk to patients during cardiac radiological procedures. Br J Radiol 1986; 59: 359-363

9. Rao UV, Vanajakshamma V, Rajasekhar D, Lakshmi AY, Reddy RN. Magnetic resonance angiography vs. angiography in tetralogy of Fallot. Asian Cardiovasc Thorac Ann. 2013 Aug;21(4):418-25.

10. Geva T, Greil GF, Marshall AC, Landzberg M, Powell AJ.Gadolinium-enhanced 3-dimensional magnetic resonance angiography of pulmonary blood supply in patients with complex pulmonary stenosis or atresia: comparison with x-ray angiography. Circulation. 2002 Jul 23;106(4):473-8.

11. Taylor AM, Thorne SA, Rubens MB, Jhooti P, Keegan J, Gatehouse PD, Wiesmann F, Grothues F, Somerville J, Pennell DJ. Coronary artery imaging in grown up congenital heart disease: complementary role of magnetic resonance and x-ray coronary angiography. Circulation. 2000; 101:1670 -1678.

12. Post JC, van Rossum AC, Bronzwaer JG, de Cock CC, Hofman MB, Valk J, Visser CA. Magnetic resonance angiography of anomalous coronary arteries. A new gold standard for delineating the proximal course? Circulation. 1995;92:3163-3171.

13. Bluemke DA, Achenbach S, Budoff M, Gerber TC, Gersh B, Hillis LD, Hundley WG, Manning WJ, Printz BF, Stuber M, Woodard PK. Noninvasive coronary artery imaging: magnetic resonance angiography 
and multidetector computed tomography angiography: a scientific statement from the american heart association committee on cardiovascular imaging and intervention of the council on cardiovascular radiology and intervention, and the councils on clinical cardiology and cardiovascular disease in the young. Circulation. $2008 \mathrm{Jul} 29 ; 118(5): 586-606$. doi:

10.1161/CIRCULATIONAHA.108.189695. Epub 2008 Jun 27.

14. Chiribiri A, Botnar RM, Nagel E. Magnetic resonance coronary angiography: where are we today? Curr Cardiol Rep. 2013 Feb;15(2):328. doi: 10.1007/s11886-012-0328-0.

15. Botnar RM, Stuber M, Danias PG, Kissinger KV, Manning WJ. Improved coronary artery definition with T2-weighted, free-breathing, three-dimensional coronary MRA. Circulation. 1999 Jun 22;99(24):313948.

16. Mavrogeni S, Markousis-Mavrogenis G, Kolovou G. Contribution of cardiovascular magnetic resonance in the evaluation of coronary arteries. World Journal of Cardiology2014;6(10):1060-1066. doi:10.4330/wjc.v6.i10.1060.

17. Cohen P, O'Gara PT. Coronary artery aneurysms: a review of the natural history, pathophysiology, and management. Cardiol Rev. 2008 Nov-Dec;16(6):301-4. doi: 10.1097/CRD.0b013e3181852659.

18. Soliman M1, Laxer R, Manson D, Yeung R, Doria AS. Imaging of systemic vasculitis in childhood. Pediatr Radiol. 2015 Jul;45(8):1110-25. doi: 10.1007/s00247-015-3339-3. Epub 2015 Jul 22.

19. Mavrogeni S. Coronary artery ectasia: from diagnosis to treatment. Hellenic J Cardiol. 2010 MarApr;51(2):158-63.

20. Greil GF, Seeger A, Miller S, Claussen CD, Hofbeck M, Botnar RM, Sieverding L. Coronary magnetic resonance angiography and vessel wall imaging in children with Kawasaki disease. Pediatr Radiol. 2007 Jul;37(7):666-73. Epub 2007 May 31.

21. Mavrogeni S, Papadopoulos G, Douskou M, Kaklis S, Seimenis I, Baras P, Nikolaidou P, Bakoula C, Karanasios E, Manginas A, Cokkinos DV. Magnetic resonance angiography is equivalent to X-ray coronary angiography for the evaluation of coronary arteries in Kawasaki disease. J Am Coll Cardiol. 2004 Feb 18;43(4):649-52.

22. Manning WJ, Li W, Edelman RR. A preliminary report comparing magnetic resonance coronary angiography with conventional angiography. N Engl J Med. 1993 Mar 25;328(12):828-32.

23. Hamdan A, Asbach P, Wellnhofer E, Klein C, Gebker R, Kelle S, Kilian H, Huppertz A, Fleck E. A prospective study for comparison of MR and CT imaging for detection of coronary artery stenosis. JACC Cardiovasc Imaging. 2011 Jan;4(1):50-61. doi: 10.1016/j.jcmg.2010.10.007.

24. Yeon SB, Sabir A, Clouse M, Martinezclark PO, Peters DC, Hauser TH, Gibson CM, Nezafat R, Maintz D, Manning WJ, Botnar RM. Delayed-enhancement cardiovascular magnetic resonance coronary artery wall imaging: comparison with multislice computed tomography and quantitative coronary angiography. J Am Coll Cardiol. 2007 Jul 31;50(5):441-7. Epub 2007 Jul 13.

25. Kim RJ, Wu E, Rafael A, Chen EL, Parker MA, Simonetti O, Klocke FJ, Bonow RO, Judd RM: The use of contrast-enhanced magnetic resonance imaging to identify reversible myocardial dysfunction. $\mathrm{N}$ Engl J Med 343(20):1445-1453. Nov 162000. 
26. McCrohon JA, Moon JC, Prasad SK, McKenna WJ, Lorenz CH, Coats AJ, Pennell DJ: Differentiation of heart failure related to dilated cardiomyopathy and coronary artery disease using gadoliniumenhanced cardiovascular magnetic resonance. Circulation 108(1):54-59. Jul 82003.

27. Monney P, Piccini D, Rutz T, Vincenti G, Coppo S, Koestner SC, Sekarski N, Di Bernardo S, Bouchardy J, Stuber M, Schwitter J. Single centre experience of the application of self-navigated 3D whole heart cardiovascular magnetic resonance for the assessment of cardiac anatomy in congenital heart disease. J Cardiovasc Magn Reson. 2015 Jul 9; 17:55. doi: 10.1186/s12968-015-0156-7.

28. Kato S, Kitagawa K, Ishida N, Ishida M, Nagata M, Ichikawa Y, Katahira K, Matsumoto Y, Seo K, Ochiai $R$, Kobayashi Y, Sakuma H.Assessment of coronary artery disease using magnetic resonance coronary angiography: a national multicenter trial. J Am Coll Cardiol. 2010 Sep 14;56(12):983-91. doi: 10.1016/j.jacc.2010.01.071.

29. Gerber BL, Raman SV, Nayak K, Epstein FH, Ferreira P, Axel L, Kraitchman DL. Myocardial first-pass perfusion cardiovascular magnetic resonance: history, theory, and current state of the art. J Cardiovasc Magn Reson. 2008 Apr 28; 10:18. doi: 10.1186/1532-429X-10-18.

30. Kellman P, Arai AE. Imaging sequences for first pass perfusion -a review. J Cardiovasc Magn Reson. 2007;9(3):525-37.

31. Wolff SD, Schwitter J, Coulden R, Friedrich MG, Bluemke DA, Biederman RW, Martin ET, Lansky AJ, Kashanian F, Foo TK, Licato PE, Comeau CR. Myocardial first-pass perfusion magnetic resonance imaging: a multicenter dose-ranging Circulation. 2004; 110:732-737.

32. Su MY,Yang KC, Wu CC. First-pass myocardial perfusion cardiovascular magnetic resonance at 3 Tesla. J Cardiovasc Magn Reson. 2007;9(4):633-44

33. Keegan J. Coronary artery wall imaging. J Magn Reson Imaging. 2015 May;41(5):1190-202.

34. McConnell MV, Ganz P, Selwyn AP, Li W, Edelman RR, Manning WJ. Identification of anomalous coronary arteries and their anatomic course by magnetic resonance coronary angiography. Circulation 1995; 92:3158-3162.

35. Taylor AM, Dymarkowski S, Hamaekers P. MR coronary angiography and late-enhancement myocardial MR in children who underwent arterial switch surgery for transposition of great arteries. Radiology. 2005 Feb;234(2):542-7. Epub 2004 Dec 10

36. Helbing WA, de Roos A. Clinical applications of cardiac magnetic resonance imaging after repair of tetralogy of Fallot. Pediatr Cardiol. 2000 Jan-Feb;21(1):70-9.

37. Sridharan S, Coats L, Khambadkone S, et al. Transcatheter Right Ventricular Outflow Tract Intervention, The Risk to the Coronary Circulation. Circulation. 2006; 113: e934-e935

\section{Tables}

Table 1. Pre-CMR diagnosis $(n=81)$ 


\begin{tabular}{|c|c|}
\hline Diagnosis & Number of subjects (\%) \\
\hline Tetralogy of Fallot & $24 / 81(30 \%)$ \\
\hline Suspected coronary artery anomaly & $15 / 81(19 \%)$ \\
\hline Ventricular septal defect & $12 / 81(15 \%)$ \\
\hline Chest pain & $10 / 81(12 \%)$ \\
\hline d-TGA & $9 / 81(11 \%)$ \\
\hline Kawasaki disease & $5 / 81(6 \%)$ \\
\hline Single cases: & $5 / 81(6 \%)$ \\
\hline \multicolumn{2}{|l|}{ Asymmetric septal hypertrophy } \\
\hline \multicolumn{2}{|l|}{ Double outlet right ventricle } \\
\hline \multicolumn{2}{|l|}{ Dilated right ventricle } \\
\hline \multicolumn{2}{|l|}{ Aortic valve disease } \\
\hline \multicolumn{2}{|l|}{ Dextrocardia } \\
\hline \multicolumn{2}{|l|}{ Dysplastic pulmonary valve } \\
\hline Syncopal episode & $4 / 81(5 \%)$ \\
\hline Coarctation of aorta & $4 / 81(5 \%)$ \\
\hline Marfan's syndrome & $3 / 81(4 \%)$ \\
\hline Bicuspid aortic valve & $3 / 81(4 \%)$ \\
\hline LV non-compaction & $3 / 81(4 \%)$ \\
\hline Truncus Arteriosus & $3 / 81(4 \%)$ \\
\hline AV canal defect & $2 / 81(2 \%)$ \\
\hline Duchenne's muscular dystrophy & $2 / 81(2 \%)$ \\
\hline Aortic root dilation & $2 / 81(2 \%)$ \\
\hline
\end{tabular}

Abbreviations: d-TGA: Dextro-transposition of great arteries, LV = Left ventricle, AV = Atrioventricular Table 2 - CMR general findings 


\begin{tabular}{|lllllll|}
\hline & $\begin{array}{l}\text { Good } \\
\text { diagnostic } \\
\text { quality of } \\
\text { images }\end{array}$ & $\begin{array}{l}\text { Patency of } \\
\text { LCA ostium } \\
\text { and course }\end{array}$ & $\begin{array}{l}\text { Patency of } \\
\text { RCA ostium } \\
\text { and course }\end{array}$ & $\begin{array}{l}\text { First pass } \\
\text { perfusion } \\
\text { defect }\end{array}$ & $\begin{array}{l}\text { DME } \\
\text { study } \\
\text { performed }\end{array}$ & $\begin{array}{l}\text { Abnormal } \\
\text { DME } \\
\text { study }\end{array}$ \\
\hline $\begin{array}{l}\text { Number } \\
\text { of }\end{array}$ & $73 / 81$ & $76 / 81$ & $72 / 81$ & $2 / 81$ & $67 / 81$ & $19 / 67$ \\
$\begin{array}{l}\text { subjects } \\
\text { (\%) }\end{array}$ & $(90 \%)$ & $(94 \%)$ & $(89 \%)$ & $(2.5 \%)$ & $(83 \%)$ & $(28 \%)$ \\
\hline
\end{tabular}

Abbreviations: $\mathrm{DME}=$ Delayed myocardial enhancement, $\mathrm{LCA}=$ Left coronary artery, RCA $=$ Right coronary artery

Table 3 - Coronary artery description $(n=81)$ 


\section{Description}

Number of patients

Clockwise rotation of coronary artery origins

Prominent conal branch which arises from proximal RCA and courses anteriorly around RVOT

LAD runs close to posterior aspect of RVOT

LAD in close proximity behind pulmonary homograft

Non Visualization of one of the coronary arteries (image quality affected by artifacts, fast heart rate or patient motion)

Abnormal coronary artery origin

- RCA arises leftward from left coronary sinus and courses between RVOT region and aorta

- LCA arises from right facing sinus close to RCA and takes interarterial course

- Both coronaries arise from right cusp

- LCA from right posterior cusp with retroaortic course.

- Single coronary ostium from which RCA and LCA arise 1

- Fusion of right and left coronary cusps

- Single coronary artery system with RCA arising from LCA and taking retroaortic course.

20

13

7

7

7

9

3

1

1

1

1

1

1

Coronary aneurysmal malformations

5

$6 \%$

$25 \%$

$16 \%$

$9 \%$

$9 \%$

$9 \%$

$11 \%$

3

(1)

- Giant long segment aneurysm of the RCA

- Aneurysm of left coronary system at LCA and LAD

- Fusiform aneurysmal dilatation of proximal LAD coronary artery

- Coronary aneurysm involving long segment of RCA

- Aneurysmal dilatation of proximal RCA.

RCA is smaller in size than LCA

5

RCA appears to arise from left coronary sinus and travels between aortic root and RVOT

Re-implanted LCA appears prominent at its origin

Patent unroofed LCA

Severe narrowing of proximal RCA

Left circumflex artery arises from RCA and takes retroaortic course

Partial fusion of the left and posterior coronary cusps

RCA travels between native RVOT and the RV-PA homograft.

RCA travels between aortic root and RVOT

1

1

$\%$

$1 \%$ 
Abbreviations: $L A D=$ Left anterior descending, $L C A=L$ eft coronary artery, $L V=$ Left ventricle, $R C A=$ Right coronary artery, RVOT=Right ventricular outflow tract, RV-PA = Right ventricle to Pulmonary artery

Table 4 - Pre CMR Suspected coronary artery anomaly 


\begin{tabular}{|c|c|c|c|c|c|c|}
\hline $\begin{array}{l}\text { Subject } \\
\text { Number }\end{array}$ & Age & Sex & $\begin{array}{l}\text { Pre CMR } \\
\text { Diagnosis }\end{array}$ & $\begin{array}{l}\text { Patency } \\
\text { of LCA } \\
\text { ostium } \\
\text { and } \\
\text { course } \\
\text { visualized }\end{array}$ & $\begin{array}{l}\text { Patency } \\
\text { of RCA } \\
\text { ostium } \\
\text { and } \\
\text { course } \\
\text { visualized }\end{array}$ & Comment \\
\hline 1 & 17 & Male & $\begin{array}{l}\text { Asymmetric } \\
\text { septal } \\
\text { hypertrophy, } \\
\text { mild aortic root } \\
\text { dilation }\end{array}$ & Yes & Yes & Normal coronaries. \\
\hline 6 & 14 & Male & $\begin{array}{l}\text { Bicuspid aortic } \\
\text { valve }\end{array}$ & Yes & Yes & $\begin{array}{l}\text { Bicuspid aortic valve with } \\
\text { fusion of right and left } \\
\text { coronary cusps. Left } \\
\text { ward origin of RCA from } \\
\text { right coronary cusp close } \\
\text { to fused right-left } \\
\text { commissure. Rightward } \\
\text { origin of LCA from left } \\
\text { coronary cusp close to } \\
\text { the fused left-right } \\
\text { commissure }\end{array}$ \\
\hline 13 & 14 & Male & Chest pain & Yes & Yes & $\begin{array}{l}\text { LCA arises close to } \\
\text { sinotubular junction. } \\
\text { Otherwise normal main } \\
\text { coronary artery and } \\
\text { branches }\end{array}$ \\
\hline 28 & 12 & Female & $\begin{array}{l}\text { Intermittent } \\
\text { syncopal } \\
\text { episodes }\end{array}$ & Yes & $\begin{array}{l}\text { Not } \\
\text { visualized }\end{array}$ & $\begin{array}{l}\text { Proximal RCA and origin } \\
\text { not well seen due to } \\
\text { dental braces. Normal } \\
\text { LCA }\end{array}$ \\
\hline 32 & 15 & Male & $\begin{array}{l}\text { Syncopal } \\
\text { episodes during } \\
\text { exercise and } \\
\text { suspected } \\
\text { anomalous } \\
\text { origin of RCA by } \\
\text { echocardiogram }\end{array}$ & Yes & Yes & $\begin{array}{l}\text { RCA arises from left } \\
\text { coronary sinus and } \\
\text { travels between aortic } \\
\text { root and RVOT. LCA } \\
\text { arises from left coronary } \\
\text { sinus. The } 2 \text { coronary } \\
\text { arteries have } 2 \text { separate } \\
\text { ostia. }\end{array}$ \\
\hline 42 & 14 & Female & $\begin{array}{l}\text { Syncopal } \\
\text { episode during } \\
\text { exercise and } \\
\text { chest pain }\end{array}$ & Yes & Yes & $\begin{array}{l}\text { Clockwise rotation of the } \\
\text { origin of coronary } \\
\text { arteries }\end{array}$ \\
\hline 54 & 13 & Female & $\begin{array}{l}\text { Chest pain and } \\
\text { shortness of } \\
\text { breath. } \\
\text { Suspected } \\
\text { anomalous } \\
\text { origin of RCA by } \\
\text { echocardiogram }\end{array}$ & Yes & Yes & $\begin{array}{l}\text { Normal origin and } \\
\text { proximal course of } \\
\text { coronary arteries. }\end{array}$ \\
\hline 60 & 18 & Female & Chest pain & Yes & Yes & RCA arises from left \\
\hline
\end{tabular}




\begin{tabular}{|c|c|c|c|c|c|c|}
\hline & & & $\begin{array}{l}\text { during exercise } \\
\text { and suspected } \\
\text { anomalous } \\
\text { origin of RCA } \\
\text { from left } \\
\text { coronary sinus } \\
\text { by } \\
\text { echocardiogram }\end{array}$ & & & $\begin{array}{l}\text { coronary sinus and } \\
\text { travels between aortic } \\
\text { root and RVOT. It takes a } \\
\text { tangential course at its } \\
\text { origin. Proximal RCA } \\
\text { segment appears to take } \\
\text { intramural course. The } 2 \\
\text { coronary arteries appear } \\
\text { to have } 2 \text { separate ostia. }\end{array}$ \\
\hline 63 & 13 & Female & $\begin{array}{l}\text { Suspected } \\
\text { anomalous } \\
\text { right coronary } \\
\text { artery origin. No } \\
\text { history of chest } \\
\text { pain or } \\
\text { syncope. }\end{array}$ & Yes & Yes & $\begin{array}{l}\text { Normal origin and } \\
\text { proximal course of the } \\
\text { main coronary arteries }\end{array}$ \\
\hline 65 & 15 & Female & Chest pain & Yes & Yes & $\begin{array}{l}\text { Normal origin and } \\
\text { proximal course of } \\
\text { coronary arteries. Normal } \\
\text { biventricular systolic } \\
\text { function with no } \\
\text { evidence of any regional } \\
\text { wall motion abnormality. }\end{array}$ \\
\hline
\end{tabular}

Abbreviations: $L C=$ left coronary, LCA=Left coronary artery, LV= Left ventricle, RCA = Right coronary artery, RVOT=Right ventricular outflow tract

Figures 


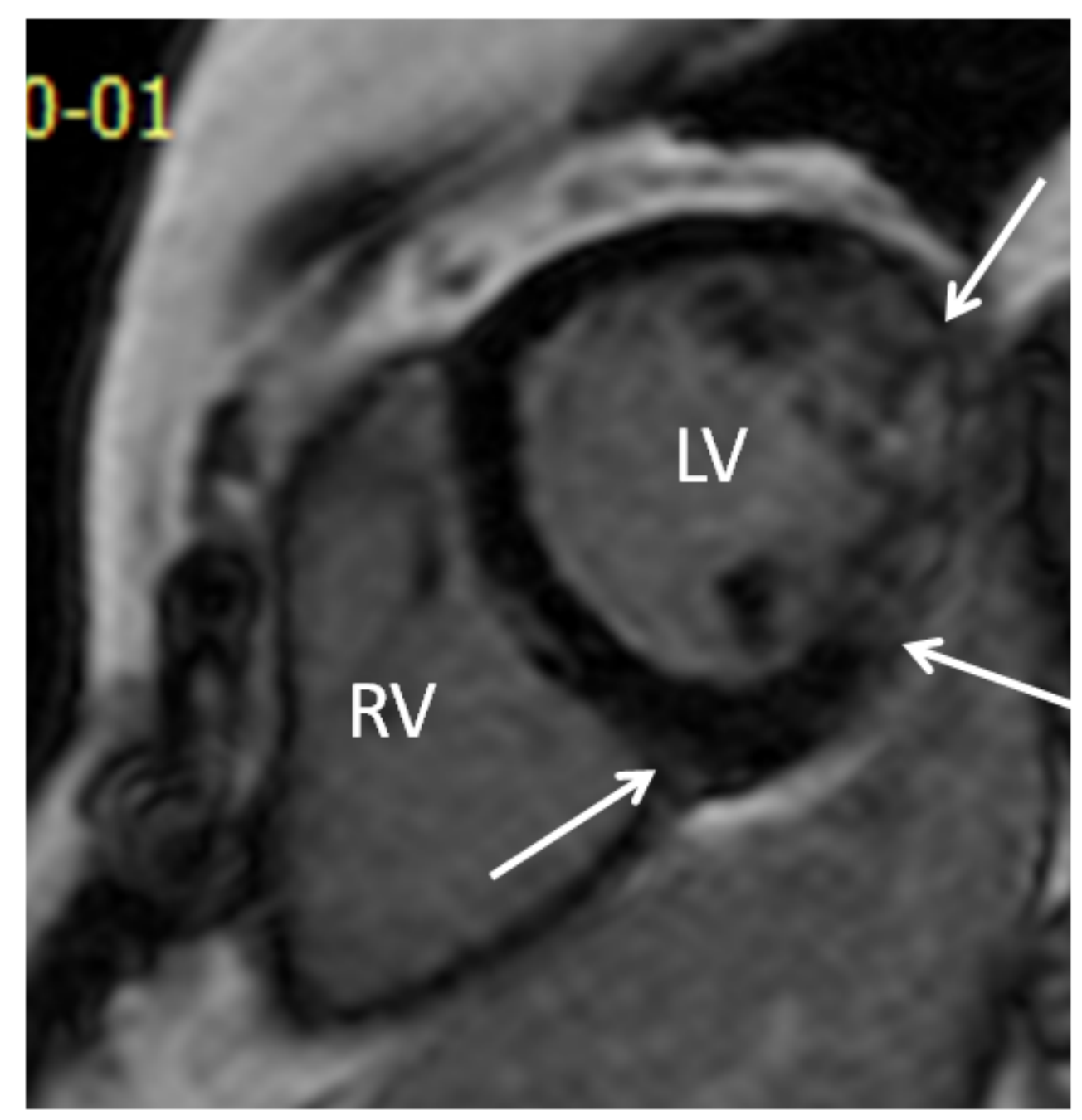

\section{Figure 1}

Inversion recovery late gadolinium enhancement study showing extensive myocardial fibrosis involving left ventricular wall and interventricular septum in a 10-year-old patient with Duchenne's muscular dystrophy. LV: Left Ventricle, RV: Right ventricle. 


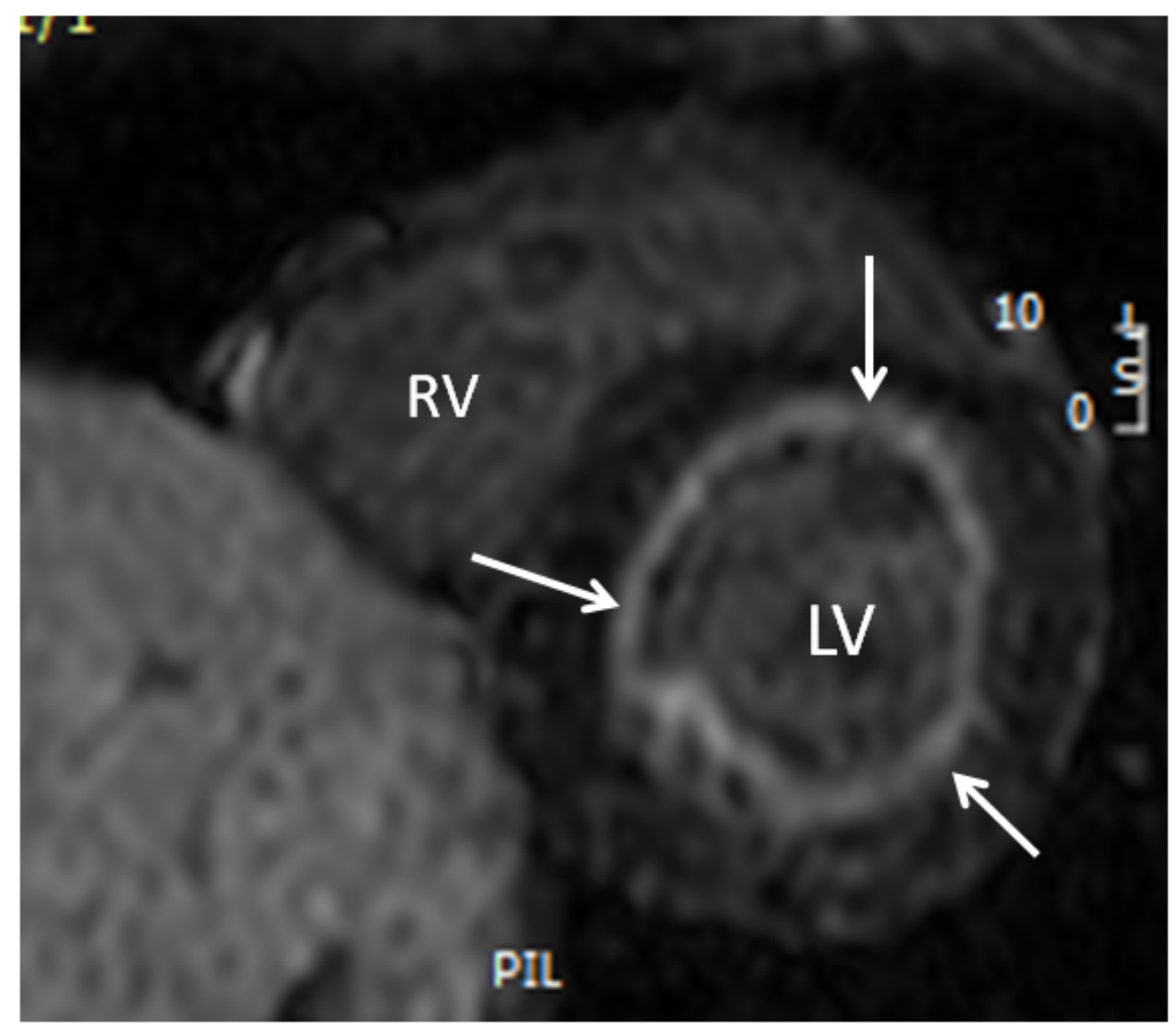

Figure 2

Inversion recovery late gadolinium enhancement study showing diffuse circumferential subendocardial fibrosis (white arrows) in a six-year-old patient with aortic valve stenosis. LV: Left Ventricle, RV: Right ventricle. 

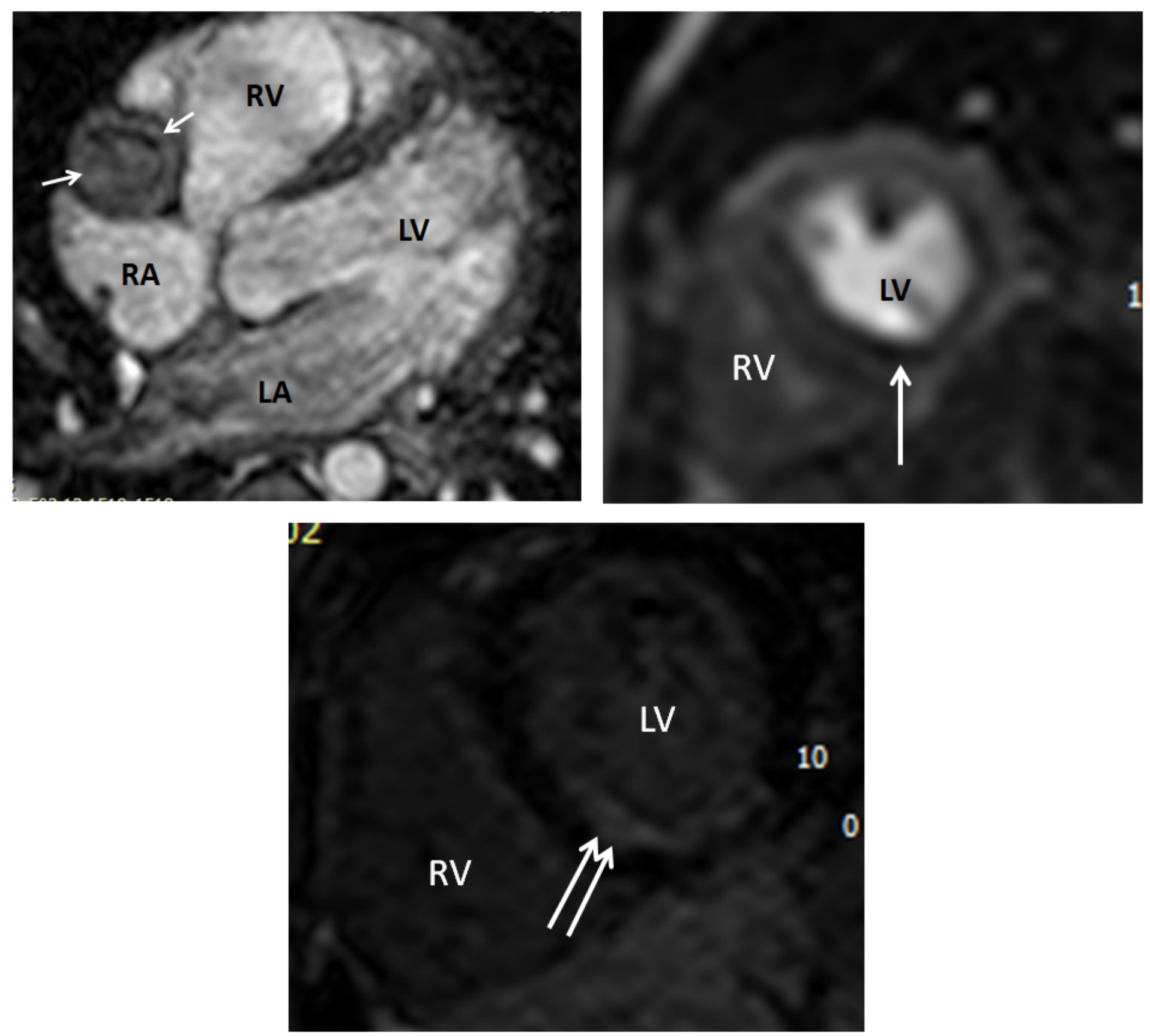

\section{Figure 3}

Whole heart T2 prep coronary imaging of a 5-year-old patient with Kawasaki disease showing a giant aneurysm of right coronary artery in right atrioventricular groove (arrows) with occlusive thrombus in the lumen (upper left image). First-pass myocardial perfusion defect (white arrow) in the same patient, showing partial occlusion of right coronary artery (upper right image). The first-pass myocardial perfusion defect corresponds to subendocardial late gadolinium enhancement (double white arrows) (inferior image). LA: Left atrium, LV: Left Ventricle, RA: Right atrium, RV: Right ventricle. 


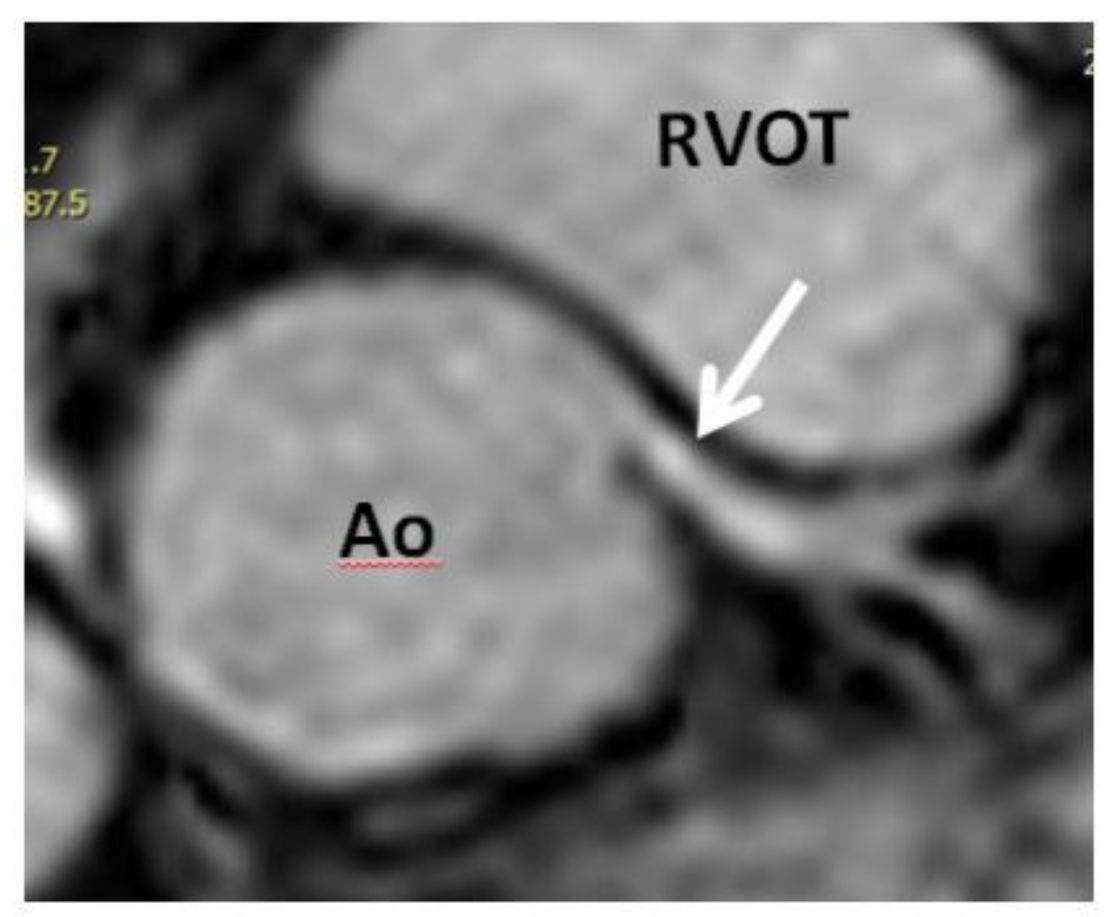

\section{Figure 4}

T2 prep whole heart CMR angiography in a six-year-old patient with anomalous origin of left coronary artery (white arrow) from right coronary sinus of Valsalva with inter-arterial course who underwent unroofing of the coronary artery. Ao: Aorta; RVOT: Right ventricular outflow tract. 

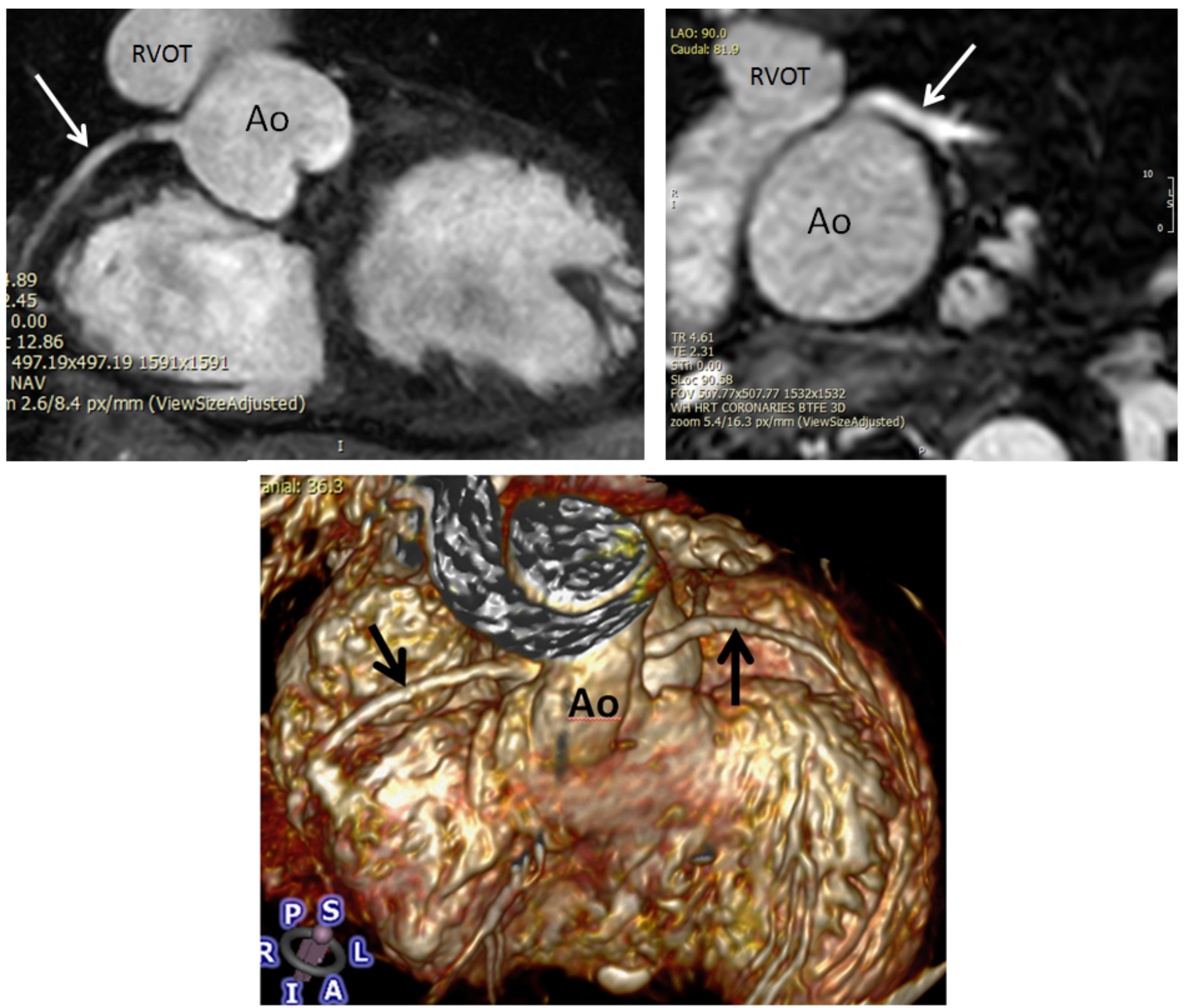

\section{Figure 5}

T2 prep whole heart CMR angiography showing re-implanted coronary arteries (white arrows) with volume rendered reconstruction image (black arrows) in a sixteen-year-old patient after arterial switch operation for dextro transposition of great arteries. Ao: Aorta; RVOT: Right ventricular outflow tract 


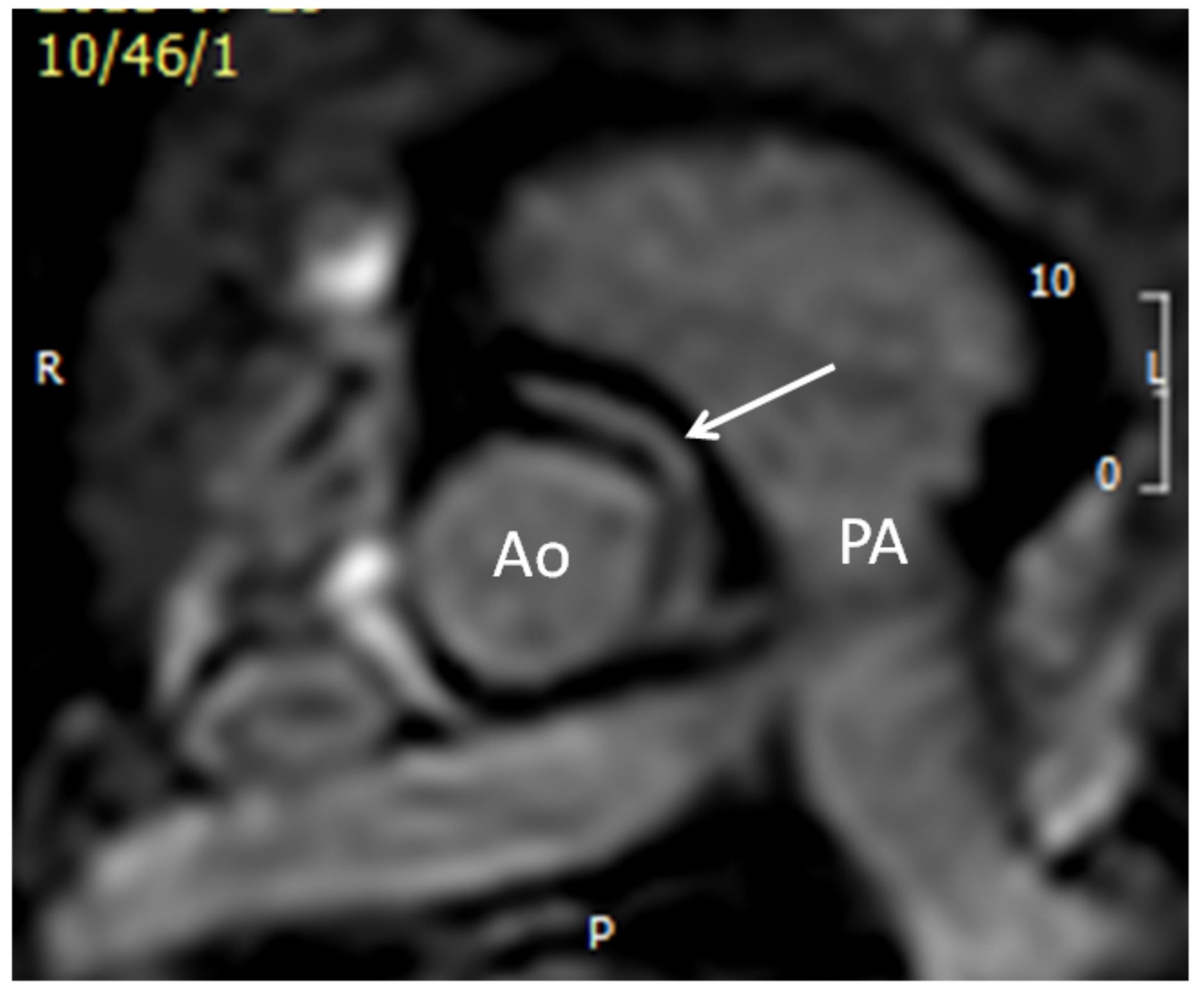

Figure 6

T2 prep whole heart CMR angiography of fifteen-year-old patient showing anomalous origin of right coronary artery from left coronary sinus of Valsalva with inter arterial course (white arrow). Ao : Aorta, PA: Pulmonary artery. 